\title{
A DECISÃO DO STF NA ADPF 153 (LEI DE ANISTIA)
}

The Supreme Court decision in ADPF 153 (Amnesty Law)

\section{Vladmir Oliveira da Silveira}

Pós-Doutor em Direito pela UFSC. Doutor e Mestre em Direito pela PUC-SP. Professor da PUC-SP e da Uninove. Diretor do Centro de Pesquisa em Direito da Uninove. Presidente do Conselho Nacional de Pós-Graduação em Direito - Conpedi.

\section{Samantha Ribeiro Meyer-Pflug}

Doutora e Mestre em Direito pela PUC-SP. Coordenadora e Professora do Curso de Direito da Uninove. Membro do Conselho Superior de Estudos Jurídicos da Federação do Comércio - Fecomercio-SP.

ÁreA do Direito: Constitucional; Internacional

ReSUmo: Analisa-se aqui a decisão do STF proferida na ADPF 153 que versava sobre a recepção da Lei de Anistia em face da Constituição Federal de 1988. Alegava-se que teor da referida lei violava o princípio democrático, republicano e a dignidade da pessoa humana e que os atos de violação da dignidade humana não se legitimam mediante uma reparação pecuniária concedida às vitimas ou aos seus familiares. O STF decidiu por maioria, pela recepção da Lei de Anistia pela atual Constituição tendo em vista o caráter amplo e geral desse instituto. Examinam-se os
ABSTRACT: We analyze here the decision of the Supreme Court rendered the claim of breach of fundamental precept n. 153 which dealt with the reception of the Amnesty Act in the face of the 1988 Federal Constitution. It was alleged that the content of that law violates the democratic principle, Republican and dignity of the human person and that acts of violation of human dignity not by a legitimate financial compensation granted to the victims or their families. The Supreme Court decided by a majority, for the acceptance of the Amnesty 
efeitos dessa decisão de caráter erga omnes e vinculante no sistema jurídico brasileiro e precipuamente em face da instauração da Comissão da Verdade no âmbito da Casa Civil da Presidência da República.

Palavras-chave: Recepção Lei de Anistia - Direito à memória - Comissão da Verdade.
Law by the current Constitution in view of the broad and general character of this institution. We examine here the effects of this decision and binding erga omnes character in the Brazilian legal system and precipuamente in the face of the establishment of the Truth Commission as part of the Civil House of the Presidency.

KeYwords: Reception amnesty law - Right to memory - Truth Commission.

SumÁrio: A) Acórdão - B) Comentário.

\section{A) Acórdão}

$$
\begin{aligned}
& \text { STF - ADPF 153/DF- Sessão Plenária - j. 29.04.2010 - m.v. } \\
& \text { - rel. Min. Eros Grau - Dje 06.08.2010 - Área do Direito: } \\
& \text { Constitucional. }
\end{aligned}
$$

\section{ANISTIA POLÍTICA - Extensão aos crimes comuns praticados por agentes do Estado no período militar - Admissibilidade - Dúvida na interpretação da expressão "crimes conexos", descrita na Lei da Anistia, e a amplitude de sua proteção - Norma que visa albergar todos os delitos que estão re- lacionados politicamente com o Estado de exceção - Constituição Federal de 1988 , ademais, que recepciona referida lei - Inteligência do art. $1 .{ }^{\circ}$, § $1 .^{\circ}$, da Lei $6.683 / 1979$.}

ADPF 153 - Distrito Federal.

Relator: Min. Eros Grau.

Arguentes: Conselho Federal da Ordem dos Advogados do Brasil $O A B$ - advogados:

Fábio Konder Comparato e Rafael Barbosa de Castilho.

Arguidos: Presidente da República - advogado: Advogado-Geral da União; Arguido: Congresso Nacional.

Interessados: Associação Juizes para a Democracia - advogados: Pierpaolo Cruz Bottini e outros; Centro pela Justiça e o Direito Internacional - Cejil - advogados: Helena de Souza Rocha e outros; Associação Brasileira de Anistiados Politicos - Abap - advogados: Aderson Bussinger Carvalho e outros; Associação Democrática e Nacionalista de Militares - advogados: Egon Bockmann Moreira e outros. 
Ementa Oficial: Lei 6.683/1979, a chamada "Lei de Anistia”. Art. 5. , , caput, III e XXXIII, da CF/1988; princípio democrático e princípio republicano: não violação. Circunstâncias históricas. Dignidade da pessoa humana e tirania dos valores. Interpretação do direito e distinção entre texto normativo e norma jurídica. Crimes conexos definidos pela Lei 6.683/1979. Caráter bilateral da anistia, ampla e geral. Jurisprudência do STF na sucessão das frequentes anistias concedidas, no Brasil, desde a República. Interpretação do direito e leis-medida. Convenção das Nações Unidas contra a Tortura e outros Tratamentos ou Penas Cruéis, Desumanos ou Degradantes e Lei. 9.455, de 7 de abril de 1997, que define o crime de tortura. Art. 5. ${ }^{\circ}$ XLIII, da CF/1988. Interpretação e revisão da Lei da Anistia. EC 26, de 27 de novembro de 1985, poder constituinte e "autoanistia". Integração da anistia da lei de 1979 na nova ordem constitucional. Acesso a documentos históricos como forma de exercício do direito fundamental à verdade.

1. Texto normativo e norma jurídica, dimensão textual e dimensão normativa do fenômeno jurídico. O intérprete produz a norma a partir dos textos e da realidade. A interpretação do direito tem caráter constitutivo e consiste na produção, pelo intérprete, a partir de textos normativos e da realidade, de normas jurídicas a serem aplicadas à solução de determinado caso, solução operada mediante a definição de uma norma de decisão. A interpretação/aplicação do direito opera a sua inserção na realidade; realiza a mediação entre o caráter geral do texto normativo e sua aplicação particular; em outros termos, ainda: opera a sua inserção no mundo da vida.

2. O argumento descolado da dignidade da pessoa humana para afirmar a invalidade da conexão criminal que aproveitaria aos agentes políticos que praticaram crimes comuns contra opositores políticos, presos ou não, durante o regime militar, não prospera.

3. Conceito e definição de "crime político" pela Lei 6.683/1979. São crimes conexos aos crimes políticos "os crimes de qualquer natureza relacionados com os crimes políticos ou praticados por motivação política"; podem ser de "qualquer natureza", mas [i] hão de terem estado relacionados com os crimes políticos ou [ii] hão de terem sido praticados por motivação política; são crimes outros que não políticos; são crimes comuns, porém [i] relacionados com os crimes políticos ou [ii] praticados por motivação política. A expressão crimes conexos a crimes políticos conota sentido a ser sindicado no momento histórico da sanção da lei. A chamada Lei de Anistia diz com uma conexão sui generis, própria ao momento histórico da transição para a democracia. Ignora, no contexto da Lei 6.683/1979, o sentido ou os sentidos correntes, na doutrina, da chamada conexão criminal; refere o que "se procurou", segundo a inicial, vale dizer, estender a anistia criminal de natureza política aos agentes do Estado encarregados da repressão.

4. A lei estendeu a conexão aos crimes praticados pelos agentes do Estado contra os que lutavam contra o Estado de exceção; daí o caráter bilateral da 
anistia, ampla e geral, que somente não foi irrestrita porque não abrangia os já condenados - e com sentença transitada em julgado, qual o Supremo assentou - pela prática de crimes de terrorismo, assalto, sequestro e atentado pessoal.

5. O significado válido dos textos é variável no tempo e no espaço, histórica e culturalmente. A interpretação do direito não é mera dedução dele, mas sim processo de contínua adaptação de seus textos normativos à realidade e seus conflitos. Mas essa afirmação aplica-se exclusivamente à interpretação das leis dotadas de generalidade e abstração, leis que constituem preceito primário, no sentido de que se impõem por força própria, autônoma. Não àquelas, designadas leis-medida (Massnahmegesetze), que disciplinam diretamente determinados interesses, mostrando-se imediatas e concretas, e consubstanciam, em si mesmas, um ato administrativo especial. No caso das leis-medida interpreta-se, em conjunto com o seu texto, a realidade no e do momento histórico no qual ela foi editada, não a realidade atual. É a realidade histórico-social da migração da ditadura para a democracia política, da transição conciliada de 1979, que há de ser ponderada para que possamos discernir o significado da expressão crimes conexos na Lei 6.683. É da anistia de então que estamos a cogitar, não da anistia tal e qual uns e outros hoje a concebem, senão qual foi na época conquistada. Exatamente aquela na qual, como afirma inicial, "se procurou" [sic] estender a anistia criminal de natureza política aos agentes do Estado encarregados da repressão. A chamada Lei da Anistia veicula uma decisão política assumida naquele momento - o momento da transição conciliada de 1979. A Lei 6.683 é uma lei-medida, não uma regra para o futuro, dotada de abstração e generalidade. Há de ser interpretada a partir da realidade no momento em que foi conquistada.

6. A Lei 6.683/1979 precede a Convenção das Nações Unidas contra a Tortura e Outros Tratamentos ou Penas Cruéis, Desumanos ou Degradantes - adotada pela Assembleia Geral em 10 de dezembro de 1984, vigorando desde 26 de junho de 1987 - e a Lei 9.455, de 7 de abril de 1997, que define o crime de tortura; e o preceito veiculado pelo art. 5..$^{\circ}$, XLIII, da CF/1988 - que declara insuscetíveis de graça e anistia a prática da tortura, entre outros crimes - não alcança, por impossibilidade lógica, anistias anteriormente a sua vigência consumadas. A Constituição não afeta leis-medida que a tenham precedido.

7. No Estado Democrático de Direito o Poder Judiciário não está autorizado a alterar, a dar outra redação, diversa da nele contemplada, a texto normativo. Pode, a partir dele, produzir distintas normas. Mas nem mesmo o STF está autorizado a reescrever leis de anistia.

8. Revisão de Lei de Anistia, se mudanças do tempo e da sociedade a impuserem, haverá - ou não - de ser feita pelo Poder Legislativo, não pelo Poder Judiciário.

9. A anistia da Lei de 1979 foi reafirmada, no texto da EC 26/1985, pelo Poder Constituinte da Constituição de 1988. Daí não ter sentido questionar-se se a anistia, tal como definida pela lei, foi ou não recebida pela Constituição de 
1988; a nova Constituição a [re] instaurou em seu ato originário. A EC 26/1985 inaugura uma nova ordem constitucional, consubstanciando a ruptura da ordem constitucional que decaiu plenamente no advento da Constituição de 5 de outubro de 1988; consubstancia, nesse sentido, a revolução branca que a esta confere legitimidade. A reafirmação da anistia da lei de 1979 está integrada na nova ordem, compõe-se na origem da nova norma fundamental. De todo modo, se não tivermos o preceito da lei de 1979 como ab-rogado pela nova ordem constitucional, estará a coexistir com o $\S 1 .^{\circ}$ do art. $4 .^{\circ}$ da EC 26/1985, existirá a par dele [dicção do $\S 2 .^{\circ}$ do art. $2 .^{\circ}$ da LICC]. O debate a esse respeito seria, todavia, despiciendo. A uma por que foi mera lei-medida, dotada de efeitos concretos, já exauridos; é lei apenas em sentido formal, não o sendo, contudo, em sentido material. A duas por que o texto de hierarquia constitucional prevalece sobre o infraconstitucional quando ambos coexistam. Afırmada a integração da anistia de 1979 na nova ordem constitucional, sua adequação à Constituição de 1988 resulta inquestionável. A nova ordem compreende não apenas o texto da Constituição nova, mas também a norma-origem. No bojo dessa totalidade - totalidade que o novo sistema normativo é - tem-se que "[é] concedida, igualmente, anistia aos autores de crimes políticos ou conexos" praticados no período compreendido entre 02 de setembro de 1961 e 15 de agosto de 1979. Não se pode divisar antinomia de qualquer grandeza entre o preceito veiculado pelo $\S 11^{\circ}$ do art. 4. ${ }^{\circ}$ da EC 26/1985 e a Constituição de 1988.

10. Impõe-se o desembaraço dos mecanismos que ainda dificultam o conhecimento do quanto ocorreu no Brasil durante as décadas sombrias da ditadura. ${ }^{1}$

DECISÃO - O Tribunal, por maioria, rejeitou as preliminares, vencido o Sr. Min. Marco Aurélio, que extinguia o processo, sem julgamento de mérito, por falta de interesse processual. Votou o Presidente. No mérito, após o voto do Sr. Min. Eros Grau (relator), julgando improcedente a arguição, foi o julgamento suspenso. Ausentes o Sr. Min. Joaquim Barbosa, licenciado, e o Sr. Min. Dias Toffoli, impedido na ADPF 153/DF. Falaram, pelo arguente, o Dr. Fábio Konder Comparato; pelos amici curiae, Associação Juízes para a Democracia, Centro pela Justiça e o Direito Internacional-CEJIL e Associação Democrática e Nacionalista de Militares-Adnam, respectivamente, o Dr. Pierpaolo Cruz Bottini, a Dra. Helena de Souza Rocha e a Dra. Vera Karam de Chueiri; pela Advocacia-Geral da União, o Min. Luís Inácio Lucena Adams; pelo arguido, a Dra. Gabrielle Tatith Pereira, Advogada-Geral Adjunta do Congresso Nacional e, pelo Ministério Público Federal, o Dr. Roberto Monteiro Gurgel Santos, Procurador-Geral da República. Presidência do Sr. Min. Cezar Peluso. Plenário, 28.04.2010. Decisão: Prosseguindo no julgamen-

1. Íntegra do acórdão disponível para assinantes em: [www.revistadostribunais.com.br], bem como no site do STF: [www.stf.jus.br]. 
to, o Tribunal, por maioria, julgou improcedente a arguição, nos termos do voto do relator, vencidos os Srs. Ministros Ricardo Lewandowski, que lhe dava parcial provimento nos termos de seu voto, e Ayres Britto, que a julgava parcialmente procedente para excluir da anistia os crimes previstos no art. 5. ${ }^{\circ}$, XLIII, da CF. Votou o Presidente, Min. Cezar Peluso. Ausentes o Senhor Min. Joaquim Barbosa, licenciado, e o Sr. Min. Dias Toffoli, impedido na ADPF 153/DF. Plenário, 29.04.2010.

\section{B) Comentário}

A arguição de descumprimento de preceito fundamental encontra-se expressamente prevista no art. $102, \S 11^{\circ}$, da Constituição da República, que dispõe: "A arguição de descumprimento de preceito fundamental, decorrente desta Constituição, será apreciada pelo Supremo Tribunal Federal, na forma da lei”. ${ }^{2}$

A arguição só foi aplicada após a promulgação da Lei 9.882, denominada de "Lei da Arguição" ou "Lei Celso Bastos", em 03.12.1999. É uma medida essencialmente judicial e terá por objeto evitar ou reparar lesão a preceito fundamental, resultante de ato do Poder Público. Caberá, ainda, a propositura de arguição de descumprimento de preceito fundamental quando for relevante o fundamento da controvérsia constitucional sobre lei ou ato normativo federal, estadual ou municipal, incluídos os anteriores à Constituição.

Não será admitida arguição de descumprimento de preceito fundamental quando houver qualquer outro meio eficaz de sanar a lesividade. Da simples leitura do dispositivo legal supratranscrito tem-se que não será admitida a arguição de descumprimento de preceito fundamental quando houver qualquer outro meio eficaz capaz de sanar a lesividade. ${ }^{3}$ Decidiu o STF na ADPF 33 que se deve entender por "outro meio eficaz" outra ação do controle concentrado de constitucionalidade e não toda e qualquer ação, o que acabaria por deixar a arguição sem eficácia. ${ }^{4}$

O alcance da arguição de descumprimento de preceito fundamental é bastante abrangente, pois faz referência a conceitos amplos e abstratos, tais como

2. Cf. Rothenburg, Walter Claudius. Argüição de descumprimento de preceito fundamental. In: ; Tavares, André Ramos (orgs.). Argüição de descumprimento de preceito fundamental: análises à luz da Lei n. 9.882/99. São Paulo: Atlas, 2001. p. 203.

3. Cf. Bastos, Celso Ribeiro. Curso de direito constitucional. 22. ed. Atual. por Samantha Ribeiro Meyer-Pflug. São Paulo: Malheiros, 2010. p. 558.

4. Bastos, Celso Ribeiro. Argüição de descumprimento de preceito fundamental e legislação regulamentadora. In: Tavares, André Ramos; Rothenburg, Walter Claudius (orgs.). Argüição de descumprimento de preceito fundamental: análises à luz da Lei $n$. 9.882/99. São Paulo: Atlas, 2001. p. 80. 
o "preceito fundamental decorrente desta Constituição" e "atos do Poder Público." A arguição tem o firme intuito de proteger o que há de mais relevante no sistema jurídico pátrio. Em virtude de os preceitos fundamentais não constarem expressamente do Texto Constitucional ficará a cargo da doutrina e da jurisprudência defini-los. Os preceitos fundamentais dizem respeito, portanto, às normas constitucionais essenciais e fundamentais da Constituição não importando dessa forma se são normas-regras ou normas-princípios.

O Conselho Federal da $\mathrm{OAB}$, um dos legitimados para ingressar com arguição de descumprimento de preceito fundamental, conforme previsto expressamente no art. 103, VII, impetrou a ADPF 153 perante o STF. Cumpre ressaltar apenas que o Conselho Federal da OAB é um legitimado universal, portanto, não precisa demonstrar pertinência temática na propositura da ação.

Referida ação foi proposta sob o fundamento de que a Lei de Anistia brasileira ao perdoar os crimes cometidos durante o regime militar violou o rol de direitos e garantias fundamentais elencado na Constituição de 1988, principalmente, a imprescritibilidade do crime de tortura e a proteção da dignidade da pessoa humana, bem como o direito à verdade e à memória histórica.

A ADPF 153 que questionou a recepção da Lei de Anistia, em face da Constituição Federal de 1988, fundamentou-se na violação do princípio democrático e republicano e da dignidade da pessoa humana. Alegou-se que os atos de violação da dignidade humana não se legitimam mediante uma reparação pecuniária (Leis 9.140/1995 e 10.559/2002) concedida às vítimas ou aos seus familiares, na medida em que os responsáveis por atos violentos, ou aqueles que comandaram esses atos, restariam "imunes a toda punição e até mesmo encobertos pelo anonimato".

Requereu-se ao STF que fosse conferida interpretação conforme a Constituição, para declarar que a anistia concedida pela Lei 6.683/1979 aos crimes políticos ou conexos não se estende aos crimes comuns praticados pelos agentes da repressão, contra opositores políticos, durante o regime militar.

Em suma, o cerne da ação recaiu sobre a circunstância de a Lei de Anistia proteger os agentes políticos que praticaram crimes comuns contra os opositores políticos, durante o período militar, tendo em vista a utilização do termo "crimes políticos".

O STF ao apreciar a ADPF 153 decidiu, por maioria, pela recepção da Lei de Anistia pela atual Constituição tendo em vista o caráter amplo e geral desse instituto. Entendeu a Corte Suprema que a Lei de Anistia é uma espécie de pacto que possibilitou a instauração da democracia no País. Nesse sentido ela faria parte de um acordo pré-constituinte, ou seja, constitui-se em uma condição para que fosse possível a promulgação da própria Constituição. 
A Corte Suprema ao apreciar a matéria entendeu que o argumento da violação à dignidade da pessoa humana não era válido, em face de não se constatar a "invalidade de conexão criminal que aproveitaria aos agentes políticos que praticaram crimes comuns contra opositores políticos, presos ou não, durante o regime militar". ${ }^{5}$ Decidiu o STF que são crimes conexos aos crimes políticos:

"(...) 'os crimes de qualquer natureza relacionados com os crimes políticos ou praticados por motivação política'; podem ser de 'qualquer natureza', mas (a) hão de terem estado relacionados com os crimes políticos ou (b) hão de terem sido praticados por motivação política; são crimes outros que não políticos; são crimes comuns, porém (a) relacionados com os crimes políticos ou (b) praticados por motivação política. A expressão crimes conexos a crimes políticos conota sentido a ser sindicado no momento histórico da sanção da lei." ${ }^{6}$

A Corte Suprema fixou que a Lei de Anistia aplica-se no tocante aos crimes políticos a uma denominada conexão criminal sui generis, somente aplicável e coerente a um determinado momento histórico, qual seja, a transição da ditadura para a democracia no Brasil. ${ }^{7}$ É uma conexão criminal distinta da comumente entendida. Assim sendo se estende a anistia aos crimes praticados pelos agentes do Estado contra os que lutavam contra o regime em vigor. Encontra-se aqui o caráter bilateral da anistia, ampla e geral concedida. Todavia, na visão do STF ela não foi irrestrita, na medida em que não englobou os já condenados e com sentença transitada em julgado pela prática de crimes de terrorismo, assalto, sequestro e atentado pessoal.

Também foi apreciado o significado variável, tanto no tempo, como no espaço, histórico e cultural, dos textos normativos. Tal aspecto era de supina importância para verificar a compatibilidade da Lei de Anistia em face da Constituição de 1988. Ficou consignado que a concessão da anistia é uma realidade "histórico-social da migração da ditadura para a democracia política, da transição conciliada de 1979, que há de ser ponderada para que possamos discernir o significado da expressão crimes conexos na Lei 6.683/1979. ${ }^{8}$

Entendeu o STF que a anistia só pode ser compreendida à luz daquela determinada época histórica, qual seja, a transição da ditadura para a democracia, e não como se concebe a anistia na atualidade. Nesse contexto, fixou o STF que a Lei de Anistia de 1979 reflete uma decisão política tomada naquele momento

5. STF, ADPF 153/DF, Pleno, j. 29.04.2010, rel. Min. Eros Grau.

6. Idem.

7. Cardoso, Fernando Henrique. A democracia necessária. Campinas: Papirus, 1985. p. 29.

8. STF, ADPF 153/DF, Pleno, j. 29.04.2010, rel. Min. Eros Grau. 
de transição de uma ditadura para a democracia. Trata-se de uma "lei-medida, não uma regra para o futuro, dotada de abstração e generalidade". 9

Outro aspecto apreciado na decisão foi a compatibilidade entre a Lei de Anistia e os tratados. Nesse cenário, analisou o STF que a Lei 6.683/1979 é anterior à Convenção das Nações Unidas contra a Tortura e Outros Tratamentos ou Penas Cruéis, Desumanos ou Degradantes, adotada pela Assembleia Geral em 10.12.1984, e em vigor desde 26.07.1987, portanto, não se podia exigir sua adequação a esses diplomas internacionais.

Destarte, também não é possível aplicar ao caso a Lei 9.455/1997, que define o crime de tortura, com fulcro no art. 5. ${ }^{\circ}$, XLIII, da CF/1988 e declara insuscetíveis de graça e anistia a prática da tortura, entre outros crimes. Observa-se que referida Lei não é aplicável por questões lógicas, pois as anistias foram concedidas antes de sua vigência e já se encontram consumadas. Para o STF "a Constituição não afeta leis-medida que a tenham precedido". ${ }^{10}$

A decisão do STF também levou em consideração que em um Estado Democrático de Direito não possui o Poder Judiciário, inclusive a Corte Suprema, autorização para alterar ou conferir nova redação ou redação diversa da estabelecida pela Lei de Anistia. Em síntese, entendeu-se que é proibido ao Poder Judiciário, em qualquer hipótese, reescrever ou modificar a Lei de Anistia. Deste modo, qualquer possível alteração deve ser realizada pelo poder legitimado para tanto, qual seja, o Poder Legislativo e não o Poder Judiciário.

A decisão ainda deixou claro que a EC 26/1985, manifestação do Poder Constituinte Reformador da Constituição, foi a responsável pela convocação de uma nova constituinte, e ela reafirmou a Lei de Anistia. Deste modo, tem-se que no próprio ato originário da Constituição de 1988, ou seja, em seu nascedouro, foi revalidada a Lei de Anistia na concepção do STF. Resta, portanto, excluído qualquer eventual conflito entre a Lei de Anistia e a atual Constituição. ${ }^{11}$

O STF decidiu, portanto, favoravelmente a recepção da Lei de Anistia pela nova ordem constitucional. Nesse sentido e consoante o referido acórdão é válida a anistia concedida aos autores e crimes políticos ou conexos praticados no período compreendido entre 02.09.1961 e 15.08.1979.

Todavia, no final do acórdão, o STF reconheceu que é perfeitamente compatível com a Constituição de 1988 a criação de uma Comissão da Verdade, para trazer a tona dados referentes à memória e a verdade histórica do País. Não

9. Idem.

10. Idem.

11. Idem. 
se admite, contudo, que dessa Comissão advenha qualquer responsabilização para seus autores, em face do teor da Lei de Anistia. A Corte Suprema que "impõem-se o desembaraço dos mecanismos que ainda dificultam o conhecimento do quanto ocorreu no Brasil durante as décadas sombrias da ditadura". ${ }^{12}$

Outro tema que foi analisado na decisão do STF diz respeito ao aspecto erga omnes e vinculante da decisão proferida na Arguição de Descumprimento de Preceito Fundamental sub examine. Deste modo, o efeito vinculante abrange todo o Poder Judiciário e a Administração Pública direta e indireta, federal, estadual e municipal. Referido efeito além de abarcar todos os órgãos do Poder Judiciário, abrange consoante o teor da Lei 9.882/1999 todo o Poder Público. ${ }^{13}$ Desse modo, num primeiro momento poder-se-ia erroneamente imaginar que a Lei 12.528/2011 que cria a Comissão Nacional da Verdade no Brasil violaria à decisão do STF.

Entretanto, é imperioso destacar que o efeito vinculante não se aplica ao Poder Legislativo. ${ }^{14}$ Nesse ponto é perfeitamente facultado ao Poder Legislativo promulgar uma nova lei com conteúdo idêntico ao da norma viciada..$^{15} \mathrm{Tal}$ faculdade visa garantir a autonomia legiferante do Poder Legislativo e assegurar a renovação jurídico-normativa do sistema. ${ }^{16}$

Nesse sentido, é preciso examinar que consoante o teor da Lei 12.528/2011 a Comissão da Verdade foi criada no âmbito do Poder Executivo, precisamente, na Casa Civil. Aqui cumpre indagar se não haveria um conflito entre a Lei e a

12. Idem.

13. Martins, Ives Gandra da Silva. Descumprimento de preceito fundamental: eficácia das decisões. In: Tavares, André Ramos; Rothenburg, Walter Claudius (orgs.). Argüição de descumprimento de preceito fundamental: análises à luz da Lei n. 9.882/99. São Paulo: Atlas, 2001. p. 175.

14. Cf. Meyer-Pflug, Samantha Ribeiro; Rocha, Maria Elizabeth Guimarães Teixeira. O controle abstrato nas ações diretas de inconstitucionalidade genérica e interventiva na Constituição de 1988. In: Féres, Marcelo Andrade; Carvalho, Paulo Gustavo M. (coords.). Processo nos Tribunais Superiores de acordo com a EC n. 45/2004. São Paulo: Saraiva, 2006. p. 429.

15. "A eficácia geral e o efeito vinculante de decisão, proferida pelo STF, em ação direta de constitucionalidade ou de inconstitucionalidade de lei ou ato normativo federal, só atingem os demais órgãos do Poder Judiciário e todos os do Poder Executivo, não alcançando o legislador, que pode editar nova lei com idêntico conteúdo normativo, sem ofender a autoridade daquela decisão" (AgRg no Rcl 2.617, rel. Min. Cezar Peluso, DJ 20.05.2005).

16. Cf. Meyer-Pflug, Samantha Ribeiro; Rocha, Maria Elizabeth Guimarães Teixeira. Op. cit. 
decisão do STF. Importante mencionar, no entanto, que referida Lei foi instituída em estrita observância a decisão proferida pelo Corte Interamericana de Direitos Humanos que autorizou a criação de uma Comissão de Verdade no Brasil.

Após o exame do teor da lei e do acórdão do STF tem-se que a Comissão da Verdade não fere em nada a decisão do Supremo, pois não visa condenar os autores dos crimes ocorridos durante o regime militar, mas tão somente concretizar o direito à verdade e à memória histórica. Nesse sentido, a criação da Comissão da Verdade encontra assento na própria decisão que como mencionado anteriormente suscita esses mecanismos de conhecimento relativos aos acontecimentos ocorridos no Brasil durante o período da ditadura.

A decisão do STF ainda prestigiou inegavelmente a governabilidade do País e os aspectos políticos que propiciaram a transição do regime militar para o regime democrático. Entendeu o STF que a Lei de Anistia foi uma condição sine qua non para essa transição. Nesse sentido, ela é um dos próprios fundamentos da Constituição de 1988. No entanto, ao assim decidir o STF contrariou os tratados internacionais de direitos humanos e uma tendência do direito internacional de propiciar a revisão dessas leis de anistias nos países que passaram por regime de exceção.

A decisão do STF, como visto, num primeiro momento parece ter colocado um fim a possibilidade de se investigar os crimes ocorridos durante o regime militar. No entanto há que se fazer duas ressalvas. A primeira delas é que tal decisão não transitou em julgado, uma vez que a decisão foi objeto de embargos de declaração. A segunda ressalva reside na possibilidade de o STF ao julgar os referidos embargos venha adotar a "interpretação conforme os direitos humanos", em especial, o sistema interamericano de proteção, no sentido de privilegiar o direito à verdade e à memória histórica. Pode ainda a Corte Suprema se valer do método comparativo de Peter Häberle. Ademais, o próprio Estado Constitucional Cooperativo propõe uma adequação dos ordenamentos jurídicos nacionais aos ditames do direito internacional e dos direitos humanos. Observa-se que não se pode admitir que num Estado Democrático de Direito se interprete a Constituição e as leis à revelia dos direitos humanos. Nesse mesmo sentido também não se pode admitir uma interpretação local para um direito internacional. Em outras palavras, interpretar o direito internacional a luz de uma visão local ou regionalizada do direito.

Todavia, da análise do referido acórdão constata-se que o STF, guardião da Constituição, nessa decisão não prestigiou o processo de internacionalização do Direito e a evolução do Estado-ação para o Estado Constitucional Cooperativo, dentro da Teoria da Democracia. 


\section{Pesquisas do Editorial}

\section{Veja também Doutrina}

- A anistia e os crimes contra a humanidade, de Edson Luis de Almeida Teles RBCCrim 55/315;

- Direito à memória e reparação: da inclusão jurídica das pessoas perseguidas e torturadas na ditadura militar brasileira, de Irene Patrícia Nohara - RDCl 67/125;

- Força integradora e catalizadora do sistema interamericano de proteção dos direitos humanos: desafios para a pavimentação de um constitucionalismo regional, de Flávia Piovesan - RIASP 25/321; e

- Lei de Anistia: um debate imprescindivel, de Pierpaolo Cruz Bottini e Igor Tamasauskas - RBCCrim 77/101. 